\title{
SEYLA BENHABIB COM HANNAH ARENDT CONTRA A FILOSOFIA DO SUJEITO
}

\author{
Yara Frateschi*
}

\begin{abstract}
A partir dos textos reunidos no livro Situating the self: gender, community and postmodernism in contemporary ethics (1992), sabe-se que Seyla Benhabib responde aos excessos racionalistas de Habermas e aos limites da tradição universalista moderna com uma releitura da concepção arendtiana de "pensamento alargado". Neste artigo, eu me proponho a mostrar que a presença de Arendt no pensamento de Benhabib é ainda mais radical do que parece à primeira vista, pois a autora de $A$ condição humana está na raiz do seu projeto teórico orientando o enfrentamento filosófico que Benhabib faz com a tradição, na sua primeira grande obra, Critique, norm, and utopia: a study of the foundations of Crítical theory (1986). A minha hipótese interpretativa é a de que a tese central deste livro, segundo a qual a teoria crítica é assombrada pela filosofia do sujeito, carrega as marcas da crítica arendtiana à filosofia política ocidental.
\end{abstract}

Palavras-Chave: Hannah Arendt. Seyla Benhabib. Filosofia do Sujeito. Filosofia Política. Pluralidade.

\section{INTRODUÇÃO}

As reflexões de Seyla Benhabib no âmbito da filosofia prática e da teoria crítica são profundamente impactadas - no espírito e no conteúdo - pelo pensamento de Hannah Arendt. Como sabemos a partir dos textos reunidos em Situating the self: gender, community and postmodernism in contemporary ethics (1992), a versão benhabibiana da ética do discurso, bem como a sua teoria do universalismo interativo, respondem aos excessos racionalistas de Habermas e aos limites da tradição universalista moderna com uma releitura da concep-

\footnotetext{
* Universidade Estadual de Campinas (UNICAMP). Departamento de Filosofia.

Rua Cora Coralina, S/N. Cidade Universitária. Barão Geraldo - Campinas - São Paulo. yfrateschi@gmail.com https://orcid.org/0000-0002-6435-1147

${ }^{1}$ Agradeço à Renata Romolo Brito pela inestimável ajuda com a tradução dos excertos do manuscrito "Philosophy and Politics: the problem of action and thought after the French Revolution" de Hannah Arendt, pela revisão das traduções existentes dos textos de Arendt e pela tradução dos excertos de Critique, norm, and utopia de SeylaBenhabib aqui utilizados. Agradeço à Renata, acima de tudo, pela pronta disposição para me amparar nos momentos mais difíceis da escrita filosófica. Agradeço ao Paulo Eduardo Bodziak Junior por ter chamado a minha atenção para a importância no manuscrito de 1954 e ao Bruno Nadai pela leitura cuidadosa de sempre.
}

ção arendtiana de "pensamento alargado" (Cf. Frateschi, 2014). Não que Benhabib possa concordar com Arendt do começo ao fim, afinal o suposto "modernismo relutante" arendtiano, a falta de compromisso explícito com o universalismo e com a tarefa de justificação normativa, assim como a separação excessivamente rígida entre o social e o político promovida por Arendt, oferecem sérios problemas para o compromisso universalista e feminista que Benhabib quer explicitamente assumir (Cf. Benhabib, 2000, p. 136). ${ }^{2}$ Para manifestar esta aproximação crítica com Arendt, ela admite, na Introdução de Situating the self, "pensar com Arendt contra Arendt" (Benhabib, 1992, p.11). O presente artigo se propõe a explicitar a presença de Arendt no momento que antecede à formulação, em Situating the self, da teoria

${ }^{2}$ Embora não haja espaço aqui para uma análise acurada da tese do suposto "modernismo relutante" de Hannah Arendt, ressalto que as "relutâncias" que Benhabib detecta em Arendt (com especial atencão para a separação excessivamente rígida entre o social e o político, o público e o privado) não a levam de forma alguma a afirmar que Arendt seja uma filósofa da antimodernidade: "Hannah Arend era uma modernista relutante, mas uma modernista ainda assim, que celebrou a declaração dos direitos do homem e do cidadão; que jamais questionou que as mulheres tivessem os mesmos direitos civis e políticos dos homens; que denunciou a aventura Imperialista" (....) e "celebrou a tradição revolucionária” (Benhabib, 2000, p. 138-139). 
do universalismo interativo, com base em uma revisão explicitamente arendtiana da ética do discurso. Mais precisamente, eu me proponho a voltar um pouco no percurso intelectual de Benhabib para mostrar que a presença de Arendt é mais radical do que parece à primeira vista, pois a autora de $A$ condição humana está na raiz do seu projeto teórico, orientando o enfrentamento filosófico que Benhabib faz com tradição na sua primeira grande obra, Critique, norm, and utopia:a study of the foundations of Crítical theory (1986). A minha hipótese interpretativa é a de que Arendt já está presente em momentos cruciais da reconstrução sistemática da história da teoria crítica realizada na obra de 1986 e, principalmente, na tese central segundo a qual esta tradição - de Hegel a Habermas, passando por Marx, Adorno, Horkheimer e Marcuse - é assombrada pela filosofia do sujeito.

O que dificulta a minha tarefa é que Benhabib, embora seja muito clara a respeito da sua aliança com Arendt em Situating the self, refere-se poucas vezes a ela em Critique, norm, and utopia, sendo que a maior parte das escassas referências ocorre em nota de rodapé. Na conclusão, que é o momento mais propositivo e claramente arendtiano do livro, esta sequer é mencionada nominalmente. Como a própria Benhabib admite anos mais tarde, naquelas páginas finais já estavam anunciados os temas arendtianos da narratividade, ação e pluralidade, com os quais ela trabalharia exaustivaปิ mente nos anos seguintes. ${ }^{3}$ Deixo às leitoras e i aos leitores a cogitação das razões que teriam levado a jovem Benhabib a manter Hannah Arendt às margens deste livro, que é um enArentamento com a tradição da teoria crítica e $\dot{\alpha}$ da filosofia moderna. Contento-me em trazêले -la das margens para o centro, e sugerir que a

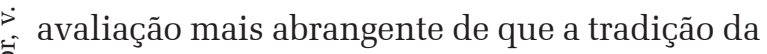
teoria crítica permanece vinculada (incluindo Habermas) à filosofia do sujeito, ecoa a crítica

3 "Entendo que a minha obra sempre esteve situada entre a minha leitura de Hannah Arendt e as minhas próprias aspirações dentro da teoria crítica; já nos últimos capítulos de Critique, norm, and utopia são anunciados os temas da narratividade, ação e pluralidade assim como o tema do outro concreto (Benhabib, 2012, p. 56). da filosofia política ocidental feita por Hannah Arendt nos anos 1950.

O enfrentamento crítico com a tradição sempre antecede à formulação de uma nova filosofia, e uma nova filosofia é sempre uma resposta aos problemas deixados pelos antecessores. O meu objetivo principal é esclarecer que Arendt e Benhabib detectam o mesmo problema de fundo nas teorias e filosofias políticas que as precederam, e sugerir que aqui está a raiz da aliança tão frutífera que Benhabib fará com Arendt nos anos seguintes e que já podemos vislumbrar nas páginas finais do livro de 1986. O que une Benhabib a Arendt é, no limite, o compromisso inegociável da filosofia arendtiana com a pluralidade humana e a desconfiança do seu sacrifício pela tradição.

A primeira seção deste artigo apresenta, em linhas gerais, o problema da filosofia do sujeito de acordo com Benhabib. A segunda seção retoma os aspectos fundamentais da crítica arendtiana à filosofia política ocidental e procura traçar paralelos entre as análises que Arendt e Benhabib fazem especialmente de Hegel e Marx. A minha intenção é sugerir que os traços centrais da caracterização que Benhabib faz da filosofia do sujeito guardam as características que Arendt detecta nas filosofias da história de Hegel e Marx. A terceira e última seção aproxima Benhabib de Arendt também na crítica que a autora de Critique, norm, and utopia endereça a Habermas que, como eu pretendo mostrar, espelha a crítica de Arendt às teorias do "progresso", sem aderir, contudo, às teorias da "ruína". Benhabib parece encontrar inspiração em Arendt também nisso, no desconforto com os extremos teóricos e na disposição para colocar em diálogo discursos filosóficos rivais (algo que na história da filosofia remete a Aristóteles e à sua busca por encontrar uma mediania teórica entre os exageros racionalistas de Platão e o relativismo exacerbado dos sofistas).

Antes de prosseguir, sugiro às leitoras e aos leitores que deixem os seus preciosismos exegéticos temporariamente adormecidos, 
pois tanto Arendt como Benhabib visitam a tradição como filósofas, não como comentadoras, exegetas ou historiadoras da filosofia e da teoria crítica. Se, porventura, elas parecerem injustas e até mesmo selvagens nas interpretações dos grandes nomes, cumpre não esquecer que ambas estão se autorizando a fazer o que fazem, em geral, os filósofos: torcem argumentos, criam espantalhos, exageram e omitem a favor das suas próprias filosofias. Isso vale para o modo como Arendt lê Platão, Hegel e Marx e também para o modo como Benhabib lê Hegel, Marx, Adorno, Horkheimer e Habermas (assim como vale para o modo como Aristóteles lê Platão, ou Marx lê Hegel e ainda Habermas lê Marx). Da minha parte, não interessa avaliar se Arendt e Benhabib estão corretas ou incorretas na maneira como interpretam esses autores, mas sugerir que a filosofia benhabibiana emerge de um diálogo filosófico com a tradição cuja marca de nascença é arendtiana.

\section{HANNAH ARENDT EM CRITIQUE, NORM, AND UTOPIA E O PROBLE- MA DA FILOSOFIA DO SUJEITO}

Não cabe nos limites deste artigo uma análise da sui generis reconstrução da história da teoria crítica à luz do problema da fundamentação normativa realizada por Benhabib em Critique, norm, and utopia. Trata-se, antes disso, de sublinhar a tese central segundo a qual esta tradição permanece presa à filosofia do sujeito, que privilegia o modelo de atividade como obra [work]. O modelo de sujeito é, desde Hegel, "um sujeito da história que constitui o processo histórico através de sua obra” (Benhabib, 1986, p.xi). Mas Hegel, de acordo com Benhabib, não está sozinho, afinal o mesmo modelo continua a ser adotado, de maneira mais ou menos evidente, por Marx, Horkheimer e Adorno. O problema é que "A filosofia do sujeito e o modelo de ação como obra privilegiam a singularidade coletiva em detrimento da pluralidade" (Idem, p. 10, grifo meu). Esta afirmação, como eu pre- tendo mostrar a seguir, vocaliza em alto e bom som a tese arendtiana de que a filosofia política, de Platão a Hegel e a Marx, prioriza o modelo da atividade humana do fazer (ou da "fabricação") (Cf. Arendt, 1992, p.121) justamente com a intenção de eliminar os elementos próprios da política e, sobretudo, a própria pluralidade humana (Arendt, 2010, p.275).

Em linhas bem gerais, a história dessa tradição é narrada por Benhabib nos seguintes termos. Marx substituiu o animal rationale de Hegel pelo animal laborans, mas permaneceu vinculado às pressuposições da filosofia do sujeito, sobretudo na medida em que reiterou o modelo da Fenomenologia de Hegel com o modelo de um "sujeito coletivo singular que cria o mundo histórico-objetivo através da sua atividade" (Benhabib, 1986, p.344). Seguindo Marx, Adorno e Horkheimer teriam continuado a aceitar a primazia do modelo da obra, e a mudança de paradigma proposta por Habermas teria finalmente alterado o modelo privilegiado de atividade - para incluir a interação comunicativa que tinha ficado de fora em todos os casos anteriores - prometendo restaurar o compromisso com a pluralidade. Contudo, apesar dos ganhos "irreversíveis" instaurados por Habermas (Benhabib, 1986, p. 346), a sua tentativa de evitar o historicismo de Hegel e de Marx não foi inteiramente feliz. Como havia acontecido com Marx, o Hegel da Fenomenologia retorna para assombrar, também, a Habermas, agora na "forma de uma reconstrução da história empírica das competências da espécie" (Benhabib, 1986, p. 346), ameaçando obscurecer um dos insights mais importantes da mudança de paradigma que ele mesmo instaurou: a ênfase na pluralidade humana.

Como fica evidente pelas considerações finais de Critique, norm, and utopia, Benhabib procura sanar o problema que se repete reiteradamente na tradição da teoria crítica com os conceitos arendtianos de pluralidade humana e estrutura narrativa e interpretativa da ação (Benhabib, 1986, p. 348). É na companhia de Arendt - ainda velada, de certa maneira - que 
ela encontrará recursos para tentar escapar da filosofia do sujeito e enfrentar o que até então os autores que a precederam não conseguiram: a pluralidade humana e tudo aquilo que a pluralidade implica, ou seja, as diferenças entre as pessoas (diferenças de identidade, história, necessidades, afetos), as diferenças de perspectivas (que resultam também de diferentes histórias narrativas nas quais as pessoas estão inseridas) e a indeterminidade interpretativa da ação. O que não é evidente é que Arendt está presente também nos momentos cruciais dessa narrativa que Benhabib constrói sobre a permanência da filosofia do sujeito na tradição da teoria crítica.

No corpo do texto há três referências à Arendt, todas breves. Benhabib se refere à irônica avaliação que ela faz da utopia da abundância sustentada por Marx (Benhabib, 1986, p. 122); faz menção à "neo-aristotélica" Hannah Arendt - que estava no horizonte de Habermas nos primeiros escritos (Benhabib, 1986, p.224); finalmente, Arendt figura ao lado de Nietzsche para exemplificar avaliações filosóficas não muito positivas da modernidade iniciada, como o era a dúvida, por Descartes (Benhabib, 1986, p. 272). ${ }^{4}$ Mas um desvio de

${ }^{4}$ Alguns anos mais tarde, Benhabib discordará das interpretações (como a de Danna Villa, por exemplo) que tentam identificar excessivamente Arendt com Nietzsche. De acordo com ela, colocar Arendt sob a sombra de Nietzsche é "subestimar a sua maior contribuição para as filosofias da ação do século XX, ou seja, a descoberta radical do vínculo entre ação, narração e intepretação” (Benhabib, 2000,

p. 197). Mas é interessante notar que a Arendt que aparece ㅇ no livro de 1986 é nomeada "neo-aristotélica" e, na longa e ๑. interminável disputa filosófica pela alma da modernidade,

$\bullet$ ela parece engrossar a fileira dos céticos, afinal "a dúvida

\& cartesiana está no início de um processo que termina com

ชิ a nossa perda do mundo" (Arendt apud Benhabib, 1986,

๑ p. 272). Não estranha inteiramente que a "neo-aristotélica"

^ Hannah Arendt, preocupada com a perda do mundo na

I modernidade, fique às margens em um livro destinado a

¿. pensar a falta de clareza, talvez endêmica, na fundamen-

tação normativa da teoria crítica, mas que, por outro lado,

๓ n não quer aceitar o ceticismo contemporâneo - sustentado

$>$ tanto pelo neo-aristotélico MacIntyre quanto pelo pós-mo-

î derno Lyortad - com relação a todo e qualquer projeto filo-

- sófico normativo inspirado em ideais modernos. Benhabib

$\stackrel{\pi}{\geq}$ claramente se opõe a este tipo de ceticismo, como fica cla-

స్ ro na seguinte passagem: "Todo programa filosófico que

- ainda busca formular um critério mínimo de conhecimen-

To e ação válidos, que ainda desenvolve conceitos de le-

G gitimidade normativa que transcende jogos de linguagem

específicos, é acusado de continuar o programa falido do

Esclarecimento (MacIntyre), de privilegiar a epistemologia

(Rorty), ou de perpetuar as meta narrativas fictícias do sé-

culo XIX (Lyotard)” (Benhabib, 1986, p.14). olhar para o rodapé mostra que a "neo-aristotélica" Hannah Arendt a conduz, desde o início do livro de 1986, na crítica da tradição moderna, especialmente, dos projetos filosóficos de Hegel e Marx. Nas notas de rodapé, a autora se refere à Arendt pela primeira vez ao sustentar que Hegel (com a "exteriorização") e Marx (com a "objetificação") subvertem o conceito aristotélico de prattein, de maneira que a "práxis deixa de significar a "prática de feitos nobres e justos"” para se tornar "um modo de atividade transformativa através da qual a externalidade é formada e apropriada para propósitos humanos" (Benhabib, 1986, p. 67, nota 29). Neste momento, Benhabib admite que a sua própria análise do conceito marxiano de práxis "é bastante devedora de Hannah Arendt em A condição humana" (Benhabib, 1986, p. 364), mas sem dar maiores explicações. ${ }^{5}$

A segunda referência aparece na nota 23 do capítulo 3, quando Benhabib analisa a Fenomenologia do Espírito para sublinhar que Hegel, embora tenha feito uma crítica promissora da moralidade kantiana, teima em adotar um modelo de ação "expressivista" que novamente obsta a consideração filosófica da intersubjetividade (Benhabib, 1986, p. 84). Hegel caracteriza a ação do Espírito (sua "obra”, que é o telos da ação) em contraste com a ação humana: a ação do Espírito, que é teleológica, elimina a incongruência entre a intenção e o feito, enquanto a ação humana permanece perpetuamente envolvida nessa incongruência, que nunca poderá ser inteiramente eliminada. Isso se deve não apenas a que o mundo "não permite a realização dos nossos propósitos”, mas também ao fato de que os outros interpretam de maneira equivocada as nossas ações (Ibidem, p. 87). O problema, então, estaria justamente na indeterminidade da ação, cujo significado e propósito é sempre determinado interpretativamente, por nós mesmos e pelos outros. "Hegel critica esta indeterminidade da ação a fim de mostrar as antinomias da

${ }^{5}$ Para uma análise posterior deste tema, conferir Benhabib (2000, capítulo 5, especialmente p. 130-138). 
consciência moral" (Benhabib, 1986, p.87). O ponto de Benhabib é que, com isso, ele revela "profunda rejeição ontológica da intersubjetividade vivida em nome de um discurso filosófico objetificante" (Ibidem, p. 87-88) ${ }^{6}$ Neste momento do texto, ao criticar explicitamente Hegel por adotar um modelo de atividade conforme a prioridade ontológica da obra sobre a ação e que visa suprir o problema da indeterminidade, Benhabib assume (em nota) seguir Hannah Arendt na seguinte passagem de $A$ condição humana:

O desvelamento do "quem" por meio do discurso e o estabelecimento de um novo início por meio da ação inserem-se sempre em uma teia já existente, onde suas consequências imediatas podem ser sentidas. (....) É em virtude dessa teia preexistente de relações humanas, com suas inúmeras vontades e intenções conflitantes, que a ação quase nunca atinge seu objetivo; mas é também graças a esse meio no qual somente a ação é real, que ela "produz" histórias [stories] intencionalmente ou não, com a mesma naturalidade que a fabricação produz coisas tangíveis. (...) Embora todos comecem a própria vida inserindo-se no mundo humano por meio da ação e do discurso, ninguém é autor da sua própria história [story] de vida (Arendt, 2010, p. 230).

Esta passagem da seção 25 de $A$ condição humana contém quase todos os elementos da teoria arendtiana da ação, dos quais Benhabib se beneficiará em Situating the self para a sua revisão da ética comunicativa que visa se livrar da filosofia do sujeito sem cair no extremo oposto de uma filosofia sem sujeito. Contento-me aqui em sublinhar que Arendt é reivindicada nessa passagem justamente como contraponto à inabilidade de Hegel de lidar com a indeterminidade interpretativa da ação, o que o leva a fechar os caminhos da intersubjetividade que ele mesmo havia prometido abrir em resposta a Kant. Para Arendt - e é nisso que Benhabib admite segui-la - é inevitável assumir que a teia

${ }^{6}$ Para uma análise detalhada da interpretação benhabibiana do legado hegeliano em Critique, norm, and utopia, conferir a tese de doutorado de Ana Claudia Lopes, Norma e utopia: A transformação da ética do discurso na teoria crítica de Seyla Benhabib. Campinas: Unicamp - IFCH, 2019, especialmente o capítulo 2 "O legado hegeliano e a posição da filosofia prática”. de relações é composta de "inúmeras vontades e intenções conflitantes" (Arendt, 2010, p. 230) e que embora os agentes se insiram no mundo por meio da ação e do discurso, "ninguém é o autor da sua própria história de vida". Assumir a "indeterminidade", sem querer a todo custo resolvê-la, é um passo filosófico imprescindível para o resgate da dignidade própria da ação, do discurso e da intersubjetividade. Enfim, em Arendt, Benhabib encontra uma aliada contra o "discurso filosófico objetificante" de Hegel e contra a sua rejeição à intersubjetividade; em Arendt, ela encontra uma aliada para se contrapor à ontologia hegeliana, de cujo ponto de vista "a indeterminidade interpretativa da ação é marca do seu status inferior" (Benhabib, 1986, p. 136). ${ }^{7}$ Pretendo que essa aliança com Arendt fique mais evidente a partir da próxima seção deste artigo.

Mas se Hegel escapa do problema adotando a perspectiva da transsubjetividade, Marx não faz muito melhor ao adotar a perspectiva da singularidade coletiva. Ou seja, nos dois casos, a adoção do modelo de ação como obra (work) - típica da filosofia do sujeito "resulta em negação da pluralidade humana" (Benhabib, 1986, p. 140). Novamente, é em Arendt que Benhabib encontra ancoramento filosófico para se contrapor à negação da pluralidade humana pelas filosofias do sujeito e definir "pluralidade":

Por pluralidade, eu não quero dizer simplesmente que nós somos corpos distintos no espaço e no tempo, mas que a nossa identidade corporificada, bem como a história narrativa que constitui nossos selves, nos dá uma perspectiva única do mundo (...) Pluralidade é a condição de seres corporificados nascidos de outros como eles mesmos. A experiência de se tornar um "Eu" necessariamente envolve a experiência de distinguir a própria perspectiva da perspectiva dos outros e isso envolve aprender como o mundo pode aparecer aos olhos do outro. É essencial para a condição descrita como pluralidade que uma pessoa alcança a própria perspectiva

${ }^{7}$ No capítulo 3 de Critique, norm, and utopia, Benhabib menciona novamente a seção 25 de $A$ condição humana em nota de rodapé ao reafirmar a indeterminidade interpretativa da ação: "a ação se desdobra dentro de uma "teia de interpretações"” (Benhabib, 1986, p. 136). 
apenas como resultado de um processo moral e cognitivo que ensina a reconhecer a presença de outras perspectivas no mundo. Parafraseando Aristóteles, apenas um deus ou uma besta não tem necessidade da perspectiva dos outros, para constituir a sua própria (Benhabib, 1986, p. 140-141, grifo meu).

Sem nenhuma explicação adicional, Benhabib se refere em nota às páginas iniciais da seção 24 de $A$ condição humana ao afirmar que "Pluralidade é a condição de seres corporificados nascidos de outros como eles mesmos", quando parece que a referência seria mais adequada na frase que vem na sequência: "A experiência de se tornar um 'Eu', necessariamente envolve a experiência de distinguir a própria perspectiva das perspectivas dos outros, e isso envolve aprender como o mundo pode aparecer aos olhos do outro". Para os propósitos deste texto, convém notar que a passagem referida sobre a revelação do agente no discurso e na ação - assim como a passagem seguinte da seção 25 sobre a teia de relações e as histórias [stories] encenadas - antecede precisamente o momento de $A$ condição humana, em que Arendt sentencia que a filosofia política, desde Platão, despreza o domínio dos assuntos humanos e que isso se deve a que os filósofos lidam mal com o "desconcertante problema de que embora a história [history] deva sua existência aos homens, obviamente, não é todavia 'feita' por eles” (Arendt, 2010, p. 232).

Além dos agentes - que se inserem no mundo humano pelo discurso e pela ação - não poderem ser considerados autores das duas próprias histórias [stories] de vida, a história [history], "em que nos engajamos enquanto vivemos, não tem criador visível nem invisível, porque não é criada” (Arendt, 2010, p.230). É para resolver este "desconcertante problema" $\therefore$ - que no limite é o exaspero do filósofo ante a "tripla frustração da ação", isto é, a imprevisibilidade dos resultados, a irreversibilidade do processo e o anonimato dos autores (Aren$\mathrm{dt}, 2010$, p. 275) - que os filósofos resolvem atribuir a "alguém" a autoria da história: à mão invisível, ao espírito do mundo, ao interesse de classe. Acontece, diz Arendt (2010, seção 31), "que todas as calamidades da ação resultam da condição humana da pluralidade" e é justamente a pluralidade que os filósofos querem eliminar e o fazem substituindo a ação pela "fabricação” (making). Aqui está, na minha interpretação, a base arendtiana da caracterização que Benhabib faz da filosofia do sujeito em Critique, norm, and utopia (e não deixa de ser curioso notar, como a passagem acima citada revela, que as duas, no momento de encontrar um espaço para a "indeterminidade" da ação, têm Aristóteles como referência filosófica de fundo).

Benhabib caracteriza a filosofia do sujeito de acordo com a adesão aos seguintes pressupostos: (1) o modelo de atividade da obra (definida como "externalização ou objetificação”); (2) o pressuposto de um sujeito transsubjetivo que se externaliza na história; (3) "a interpretação da história [history] como a história [story] da transsubjetividade" (Benhabib, 1986, p. 213); (4) a identidade de uma subjetividade constituinte e constituída (Cf. Benhabib, 1986, p. 54 e 213). Como não cabe dentro dos limites deste artigo uma análise minuciosa dessas quatro premissas, destacarei apenas alguns momentos de Critique, norm, and utopia que parecem claramente indicar a maternidade da tese mais geral do livro e mostrar que essas premissas - pelo menos as três primeiras - traduzem em termos benhabibianos os aspectos que Arendt critica nos filósofos políticos desde Platão, com especial destaque para Hegel e Marx. ${ }^{8}$

Assim como seus predecessores no campo da teoria crítica, Benhabib também critica Hegel pela concepção de história e pela imposição de um sujeito abstrato especulativo, o "Espírito". Como Arendt - quase literalmente como Arendt - Benhabib sustenta também que Marx, nos Manuscritos de 1844, "simplesmente substitui ‘Espírito' por ‘humanidade”” (Benhabib, 1986, p. 54). Para ela, eis o ponto que interessa sublinhar aqui, essa substituição "não altera os fundamentos da 'filosofia do sujeito',

${ }^{8}$ Sobre os pressupostos que constituem a filosofia do sujei-
to, conferir a tese de doutorado de Lopes (2019, p.80-81). 
pois a história continua a ser vista como um processo unitário de desdobramento das capacidades de um sujeito coletivo e a emancipação social continua a ser entendida como a reapropriação desse legado por uma classe social específica" (Benhabib, 1986, p. 54). Tanto essa passagem, como a interpretação, mais abrangente, de que o modelo hegeliano de vida ética é uma "utopia retrospectiva”, ao passo que o modelo marxiano da socialização do universal é uma "utopia prospectiva" são herdadas de Arendt que já havia sentenciado o seguinte, a respeito de Hegel e Marx:

Existe apenas uma diferença essencial entre Hegel e Marx, embora, verdade seja dita, de importância catastrófica: Hegel projetou a sua visão histórico-mundial exclusivamente para o passado e deixou sua consumação esbater-se no presente, ao passo que Marx, "profeticamente”, projetou-a, ao contrário, para o futuro e compreendeu o presente como um simples trampolim (Arendt, 2009, p.118).

Para Arendt, o fato de Hegel projetar a sua visão para o passado e Marx profetizar o futuro ("utopia restrospectiva" e "utopia prospectiva”, nas palavras de Benhabib mais de 30 anos depois) revela, nos dois casos, fuga da política. Hegel e Marx são mais semelhantes entre si do que o próprio Marx e os marxistas estariam dispostos a conceder. Retomarei a seguir, em linhas gerais, a crítica que Hannah Arendt faz, desde pelo menos o início dos anos 1950, à tradição da filosofia política ocidental, com especial destaque para a sua interpretação de Hegel e Marx. ${ }^{9}$

\section{A CRÍTICA ARENDTIANA DA FILO- SOFIA POLÍTICA: a substituição da ação pela fabricação}

Vale sublinhar dois aspectos da análise que Arendt faz da tradição da filosofia políti-

${ }^{9}$ A seguir eu reproduzo parte da análise mais ampla que fiz da crítica de Arendt à filosofia política ocidental em "Juízo e Opinião em Hannah Arendt", Cadernos de Filosofia Alemã : Crítica e Modernidade, São Paulo, v. 24, n. 1, pp. 35-65, 2019. ca ocidental: 1) salvo raríssimas exceções, os filósofos políticos - tanto antigos quanto modernos - apresentam clara hostilidade contra a pluralidade humana; 2) relacionam-se com essa hostilidade o desprezo pela ação e a preferência pela "atividade muito mais confiável do fazer” (Arendt, 1992, p. 119). Para ela, Platão, Aristóteles, Hegel e Marx priorizam o mesmo "modelo da atividade humana": a fabricação (Arendt, 1992, p. 121). Isso significa que eles tomam a poiesis e não a práxis como modelo, reduzindo a ação a uma atividade que produz objetos, reifica, constrói, fabrica. Embora Aristóteles ocupe um lugar mais ambíguo na história da filosofia de Arendt e embora ela mesma se aproprie da energia e da ação virtuosa aristotélicas para atribuir um significado para a ação distinto do significado da fabricação, no limite ele também incorreria no mesmo vício dos seus colegas filósofos. ${ }^{10} \mathrm{O}$ vício é a fuga da própria política com a expectativa de conquistar a certeza, a estabilidade e a harmonia que o mundo dos assuntos humanos simplesmente não é capaz de fornecer. O problema é que ao eliminar justamente aquilo que é próprio da política - a pluralidade - e tomar a ação como se fosse fabricação, a filosofia política torna-se uma contradição em termos.

A história da filosofia narrada pela storyteller Hannah Arendt começa com Platão, o primeiro a tornar a ação e o discurso irrelevantes e a erigir um modelo no qual a ficção do "One Man” suprime a pluralidade humana. Platão ${ }^{10}$ Como eu apontei em "Juízo e Opinião em Hannah Arendt” (Frateschi, 2019), Aristóteles ocupa um lugar mais ambíguo na história da filosofia política tal como Arendt a interpreta de Platão a Marx. Embora ela também o responsabilize pelo antagonismo entre filosofia e política, pela separação entre pensamento e ação e pela adoção do modelo da fabricação, a sua leitura de Aristóteles é mais nuançada do que esse veredicto geral nos leva a supor à primeira vista. Se Aristóteles compartilha com Platão alguns pressupostos, difere dele por entender que as duas atividades próprias da política são a ação (práxis) e o discurso (lexis) (Arendt, 2010, p. 29). O que distingue Aristó-

teles (que nisso se aproximaria de Sócrates, segundo Arendt) é que, para ele, ser um animal político "significa ter a faculdade natural do discurso" (Arendt, 1954, imagem 10), o que, para Arendt, o leva a preferir a vida na polis à realeza, à monarquia ou ao despotismo. Além do mais, Arendt se apropria da noção aristotélica de energeia para pensar a ação para além da lógica instrumental e fora da categoria meios e fins: a ação, como a virtude, é uma atividade com valor intrínseco, um fim em si mesma e não apenas meio para um outro fim (Cf. Arendt, 2010, p. 257-258). 
deu o "acorde fundamental", que "ressoa em infindáveis modulações através de toda a história do pensamento ocidental"(Arendt, 1992, p. 44): o "acorde fundamental" é uma metáfora para comunicar que a inabilidade do filósofo para lidar com o instável e o relativo reaparece reiteradas vezes ao longo da história da filosofia.

Não há espaço aqui para acompanhar passo-a-passo a análise que Arendt faz da Parábola da Caverna, mas importa sublinhar que se trata de uma história em três atos que ela interpreta como paradigmática da pretensão da filosofia de desvelar $a$ verdade e atingir um grau de objetividade e certeza que destoa radicalmente da pretensão da própria Arendt a respeito da atividade do pensamento. Para ela - que não se identificava como "filósofa", aliás (Arendt, 1993, p. 123) - a faculdade de pensar não proporciona a verdade, mas sim o significado (Cf. Arendt, 2002, p. 45 e 92). Importa sublinhar ainda que a solução que ele - o filósofo - encontra para as vicissitudes dos assuntos humanos e para as incertezas da ação é substituí-la pela fabricação (ou obra), que é uma atividade que envolve a imagem mental do produto e o cálculo dos meios para a sua produção (Cf. Arendt, 2010, p. 281; Arendt, 1954, imagem 13). Platão resolve os problemas da política pela instituição da relação entre governante e governados transformando os governados em "fabricantes" que colocam em prática os modelos e padrões estabelecidos pelo governante. A vantagem é ڤิ que deste modo os cidadãos agiriam como um บ só homem, pois, por meio do governo, "os mui¿ tos se tornam um, em todos os aspectos" (Arenฮे dt, 2010, p. 279). Ou seja, a substituição da ação רే pelo governo corresponde à redução da ação à ¿. fabricação. Mais ainda: como alerta Arendt, não लో apenas os governados "fabricam", o rei filósofo $>$ "aplica as ideais como o artesão aplica suas regras e padrões; ele 'faz' a sua cidade como o escultor faz uma estátua” (Arendt, 2010, p. 283). No terceiro ato na parábola, quando o filósofo volta para conviver com os seus semelhantes na caverna, ele (...) necessita das ideias orientadoras como padrões e regras pelas quais medir e sob as quais subsumir a variada multiplicidade de palavras e atos humanos, com a mesma certeza absoluta e "objetiva" com que o artesão pode se orientar na fabricação e o leigo no julgamento de camas individuais ao usar o modelo estável e sempre presente, a "idéia” da cama em geral (Arendt, 2010, p. 282).

Hegel transformou a metafísica tradicional na filosofia da história e permaneceu, infelizmente, ecoando o acorde de Platão. Em que sentido? No sentido de que a história conquista dignidade ("a própria história se torna o tópico autêntico da filosofia” [Arendt, 1954, imagem 30]), mas é ao preço, novamente, de suplantar o particular e a pluralidade, ${ }^{11}$ afinal, a verdade não é inerente a nenhum evento singular, mas ao processo histórico como um todo. A verdade só se revela quando a história [story] chegar ao fim. Mas o que importa à luz da narrativa deste artigo sobre as leituras que Arendt e Benhabib fazem da tradição é que, para Arendt, Hegel tornou a vida ativa sem significado para os agentes, conduzidos pelo "ardil da razão". A história é a história de um indivíduo, este "indivíduo monstruoso e gigantesco - a humanidade”, um "Homem artificial" (Arendt, 1954, imagem 31). O que os indivíduos fazem e pensam é apenas uma parcela do produto final da história. Hegel mede a multiplicidade das ações e eventos com o metro do Absoluto, "assim como Platão mediu as opiniões como o metro da verdade”. O múltiplo é sacrificado ao Um e a "pluralidade dos homens que se expressa politicamente em opiniões" (Arendt, 1954, imagem 41) é eliminada:

Assim como Platão exigia que Um Homem, o rei-filósofo que sabia a verdade, deveria governar os muitos, também Hegel exigiu que um filósofo, para

${ }^{11}$ Sobre Hegel, ela diz: “(...) na corrente gigantesca que, com o começo da humanidade civilizada, começou a revelar a verdade absoluta do Espírito em um desenvolvimento sobre-humano, os nítidos contornos dos eventos e ações são tão dissolvidos quanto a singularidade de quaisquer pensamentos particulares. Se o significado, de acordo com o passado pré-platônico dos gregos, se manifestava na ação quando e se ele se manifestava pelo discurso; se o significado, no desenvolvimento filosófico específico do Ocidente, foi então revelado como verdade contemplada, então o significado em Hegel não adere nem a ação nem ao pensamento como tal, mas apenas ao desenvolvimento histórico que submerge a ambos" (Arendt, 1954, imagens 30-1). 
cujo olhar retrospectivo o Absoluto se revela no processo do tempo, devia ser o possuidor e distribuidor do significado pelo qual todos os outros homens em seus feitos e pensamentos lutam em vão (Arendt, 1954, imagem 41, grifo meu).

O preço que a filosofia teve que pagar para reconciliar o pensamento com a realidade e tornar racional o real, foi a obliteração da pluralidade humana bem como da "variedade, da imprevisibilidade e das contradições das suas ações" (Arendt, 1954, imagem 31). Tendo sido o responsável por transformar a metafísica tradicional em filosofia da história, Hegel passou a ver a história como um "gigantesco processo de fabricação”, cujo significado é apreendido pelo olhar retrospectivo do filósofo. Parece-me inegável que a maneira pela qual Benhabib caracteriza a filosofia do sujeito e suas premissas é fortemente inspirada por esta análise que Arendt faz de Hegel e também, como veremos a seguir, de Marx.

Marx se rebela contra a tradição ao reclamar que os filósofos apenas interpretaram o mundo de diferentes maneiras, agora é preciso transformá-lo. Arendt reconhece que a insurreição é de grande porte, afinal efetivamente os filósofos até então haviam se empenhado em prescrever regras de ação para colocar ordem na desordem, mas nenhum deles elegeu como prioritária a transformação do mundo. O problema é que a rebelião de Marx contra a tradição findou em autoderrota (veremos, na última seção deste texto que Benhabib também teme que a rebelião de Habermas contra a filosofia do sujeito finde em autoderrota). Embora Marx tenha percebido o seu mundo - eis a sua grandeza - "como um mundo invadido por problemas e perplexidades novas com as quais a nossa tradição de pensamento político não era capaz de lidar" (Arendt, 1992, p. 54 ), ele terminou por repetir modos antigos de resolver as questões do seu próprio tempo. $\mathrm{O}$ acorde fundamental de Platão continua, de algum modo, a ressoar também em Marx (através de Hegel): ao substituir a ratio pelo labor e definir o homem, em contraste direto com Hegel, como animal laborans, permaneceu mais preso a Hegel do que gostaria e do que aparece à primeira vista.

Certamente ele estava imbuído - com razão, admite Arendt - da premência de atribuir à atividade do trabalho uma dignidade que a história da filosofia jamais lhe concedeu (claro, afinal como negar a centralidade do trabalho depois da Revolução Industrial?). No entanto, ainda que tenha colocado uma atividade - o trabalho - no centro das suas reflexões, o seu pensamento político "não se baseava em uma análise dos homens em ação, mas, ao contrário, na preocupação hegeliana com a História” (Arendt, 1992, p. 112). Se, com Hegel, a filosofia se torna interpretação da história, com Marx a história se torna ciência. O que ele fez, ao fim e ao cabo, foi trocar a palavra "Espírito" - o sujeito oculto do processo de fabricação de Hegel - pela palavra "Sociedade" - o sujeito do processo histórico (Benhabib repete quase a mesma formulação, como vimos). Hegel olha para o passado em busca da verdade, Marx "desenha um futuro no qual a verdade será realizada na Sociedade como um todo" (Arendt, 1954, imagem 33). A ação torna-se a mesma coisa que "fazer a história" e novamente tem o sentido de "fabricação" (Arendt, 1992, p. 112). O agente - criador do futuro - é o "fabricante da história". Para Arendt, enfim, com Hegel e Marx, nos tempos modernos a história toma o lugar da política, tornada "mera técnica de administração, manipulação e representação" (Arendt, 1954, imagem 37). Tendo prometido tornar imanente o transcendente, Marx incorpora o significado hegeliano de História - “o progressivo desdobramento e realização da ideia de liberdade - como sendo fim da ação humana” (Arendt, 1992, p. 113). A liberdade passa, assim, a ser o fim último e o "produto final” de um processo de fabricação. E assim se dá, novamente, a fuga da política e o sacrifício da pluralidade humana. ${ }^{12}$

${ }^{12}$ Infelizmente, lamenta Arendt, Marx termina resolvendo a experiência do novo "em algo velho" e a sua rebelião contra a tradição finda em autoderrota. As teses fundamentais com as quais ele contestou a tradição os conduzem a dificuldades profundas e a uma contradição fundamental. Se o trabalho define o ser humano, pergunta Arendt, que atividade humana restará com a realização da liberdade após a revolução? Esta seria, de acordo com ela, a contradição fundamental de Marx, afinal ele teria definido o homem (contra Aristóteles, contra Hegel, contra toda a tradição) como animal laborans, mas desenhou o modelo de uma sociedade na qual essa atividade não seria mais necessária (Cf. Arendt, 2010, p. 129). Se a violência é a parteira da História, qual será o significado da ação depois da resolução da luta de classes? Que tipo de pensamento restará, pergunta finalmente Arendt, quando a filosofia tiver sido finalmente realizada e o mundo transformado? E certo, admite ela, que Marx é levado a tais contradições buscando genuinamente quebrar com a tradição e encontrar um novo quadro conceitual para lidar com os problemas do seu tempo, mas não consegue completar a tarefa que impôs a si mesmo (Cf. Arendt, 1992, p. 52). Para ela, o prendem à tradição: a filosofia da história; a atribuição ao trabalho (labor) das características que são próprias da atividade da fabricação (work); a projeção de uma Sociedade harmonizada que implica a desvalorização da ação. A teoria das superestruturas parece uma grande novidade, mas carrega o mesmo preconceito que Platão tinha contra o discurso, pois em todos os campos da atividade humana - religião, legislação, arte e filosofia - considera-se que 
Certamente, Benhabib enxerga muito mais nuances em Hegel e Marx do que Arendt e, também, é mais atenta às diferenças entre as obras de juventude e as da maturidade. No entanto, interessa notar aqui que a análise minuciosa que ela faz do percurso intelectual de $\mathrm{He}-$ gel da juventude à obra madura, termina por concluir que mesmo que ele tenha mudado o método da crítica a partir de 1805, que tenha se tornado mais sensível à perspectiva da intersubjetividade, que tenha se tornado menos resistente à modernidade e deixado de contrapor "o direito de um absoluto ético às pretensões do individualismo moderno" (Benhabib, 1986, p. 44), ainda assim, as suas novas descobertas permanecem de mãos dadas com a filosofia do sujeito. Do ponto de vista metodológico, em A Fenomenologia do Espírito, o argumento continua a depender de premissas da filosofia especulativa. O principal argumento dela é o de que Hegel, na Fenomenologia do Espírito, modela a atividade da consciência na atividade do trabalho [labor] e, assim, desenvolve a "tese de que a história pode ser vista como a atividade de um sujeito coletivo singular que exterioriza a si mesmo e subsequentemente 'se re-apropria' do que exteriorizou” (Benhabib, 1986, p. 47). Esta é a posição da filosofia do sujeito, de acordo com Benhabib e, como eu pretendo sugerir, trata-se de uma formulação que ecoa o argumento arendtiano de que a típica redução filosófica da pluralidade humana จิ ao "One Man" ("sujeito coletivo singular", nas i palavras de Benhabib) vem sempre acompa¿े nhada do desprezo pela ação e a preferência \& pela "atividade muito mais confiável do fazer" 글 (Arendt, 1992, p. 121). Trata-se de uma ativi$\overrightarrow{\dot{2}}$ dade que projeta um objeto, o constrói e o colom

$>$ o discurso oculta, esconde, engana. Por fim, a teoria das ث. classes - que se baseia em um agudo discernimento histó- ria, admite Arendt - acaba se tornando uma "fórmula”, um

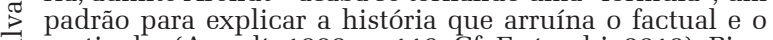
厄్ particular (Arendt, 1992, p. 116; Cf. Frateschi, 2019). Pior: a projeção da sua consumação no futuro sustenta a ficção

I de uma harmonia de interesses e pontos de vista que só

f poderia evidentemente se realizar pelo sacrifício da plura-

lidade humana. Para uma excelente análise do confronto de Arendt com Marx, conferir o livro de André Duarte O

pensamento à sombra da ruptura: política e filosofia em

ษ Hannah Arendt. São Paulo: Paz e Terra, 2000. ca no mundo. Benhabib também nota, em Critique, norm, and utopia, que na Fenomenologia do Espírito, Hegel "reduz os diferentes modos de atividade característicos da experiência da consciência, ao paradigma único da externalização" (Benhabib, 1986, p. 53), do qual o trabalho (labor) é exemplo principal.

Não se trata aqui de analisar o argumento de Benhabib minuciosamente, mas de notar o seu significado mais abrangente: a atividade da consciência é tomada como uma atividade que cria objetos. Como Arendt, ela conclui que é justamente este reducionismo das diversas atividades humanas à atividade que produz objetos que impede, no limite, que se dê um salto para a intersubjetividade, o que envolveria levar a sério, para ambas, a ação e o discurso, as vicissitudes e a indeterminidade interpretativa da ação. Mas o filósofo, como também pensa Benhabib, não apenas torna a ação humana sem sentido, mas também reduz “a experiência da pluralidade humana à memória de um sujeito transsubjetivo chamado "Espírito" (Benhabib, 1986, p. 53). Arendt havia dito isso de outro modo, referindo-se a um "individuo monstruoso e gigantesco" (Arendt, 1954, imagem 31). Para ambas, esse super sujeito, seja lá como se queria batizá-lo, significa a morte da própria política. Nas palavras de Arendt: com o metro do absoluto, Hegel sacrifica o múltiplo ao Um e elimina a "pluralidade dos homens que se expressa politicamente em opiniões" (Arendt, 1954, imagem 41).

Como Arendt, Benhabib avalia que Marx opera com os mesmos reducionismos de Hegel embora tenha feito esforço extraordinário para superá-lo. Marx, como vimos, "simplesmente substitui ‘Espírito' por 'humanidade”, (Benhabib, 1986, p. 54), uma substituição que, para Benhabib - tal como para Arendt a respeito da filosofia da história - "não altera os fundamentos da filosofia do sujeito, pois a história continua a ser vista como um processo unitário do desdobramento das capacidades de um sujeito coletivo, assim como a emancipação continua a ser vista como a re-apropriação desse legado 
por uma classe específica” (Benhabib, 1986, p.54). Sem dúvida, Benhabib enxerga mais ambigüidades em Marx do que Arendt. Para ela, haveria um importante momento democrático nos Manuscritos, que preservaria a perspectiva da pluralidade e a da intersubjetividade (Cf. Benhabib, 1986, p. 55-62). Para Arendt, em contrapartida, dos primeiros textos até o último volume de $O$ capital, Marx é perfeitamente coerente na sua hostilidade contra a política e contra a pluralidade humana (Cf. Arendt, 1992, p. 48). A despeito, entretanto, dessa importante diferença de interpretação entre Arendt e Benhabib a respeito de Marx, importa notar aqui que, para a autora de Critique, norm, and utopia, ao fim e ao cabo o que predomina em Marx, mesmo nos textos de juventude, é a adesão a um modelo de atividade (como objetificação) inevitavelmente incongruente com a pluralidade e a intersubjetividade. No limite, o conceito de objetificação de Marx é modelado pelo conceito de exteriorização de Hegel, afinal, ambos (como Arendt mostrou trinta anos antes) priorizam um modelo de atividade que não é a ação. A adesão de Marx a Hegel, de acordo com a análise de Benhabib, tem a mesma consequência daquela detectada por Arendt. Esta havia notado que, em ambos os casos, o ponto de vista dos agentes singulares e a própria ação política perdem significado e importância quando o sujeito da história é o Espírito ou a Sociedade.

Como vimos anteriormente, a primeira aparição subterrânea de Arendt em Critique, norm, and utopia acontece justamente no contexto dessa análise a respeito das semelhanças entre Marx e Hegel (inclusive na subversão que ambos fazem do conceito aristotélico de práxis) (Benhabib, 1986, p. 67, nota 29). Parece, contudo, que mais do que estar de acordo com a análise arendtiana do conceito marxiano de práxis, Benhabib incorpora na sua caracterização da filosofia do sujeito os momentos mais relevantes da crítica de Arendt à filosofia política ocidental.

No manuscrito "Philosophy and Politics", Arendt desafia os filósofos afirmando que uma reconciliação com a política exigira deles fazer da pluralidade humana "o objeto do seu espanto" (Arendt, 1954, imagem 70). Na obra de 1986, Seyla Benhabib parece disposta a aceitar o desafio arendtiano e "perseguir a perspectiva da pluralidade e da radical intersubjetividade", ciente de que, para tanto, é preciso evitar “"o vôo da filosofia' para longe da nossa situacionalidade e corporeidade” (Benhabib, 1986, p. 55). O desafio é aceito na obra de 1986 e levado adiante em Situating the self.

\section{A CRÍTICA ARENDTIANA DE BE- NHABIB A HABERMAS: o problema do "progresso"}

Para Seyla Benhabib, a Teoria Crítica situa-se em algum lugar entre as ciências sociais e a filosofia e tem duas dimensões distintas, porém, igualmente imprescindíveis para que se cumpra a sua orientação para a emancipação e transformação social: a dimensão diagnóstico-explicativa e a dimensão antecipatório-utópica (Benhabib, 1986, p. 226). A primeira, em diálogo intenso com as ciências sociais, tem a função de desenvolver análises empíricas frutíferas das crises e contradições do presente. A segunda dimensão constitui mais propriamente o aspecto normativo da teoria crítica: a explicação das disfuncionalidades do presente que deve sempre ser feita "em nome de um futuro melhor e de uma sociedade mais humana” (Benhabib, 1986, p.266):

O propósito da teoria crítica não é o manejo das crises, mas o seu diagnóstico a fim de encorajar transformação futura. A teoria crítica social vê o presente da perspectiva da transformação radical da sua estrutura básica, e interpreta as crises e os protestos reais e vividos à luz de um futuro antecipado. Em sua capacidade antecipatória-utópica, a teoria crítica aborda as necessidades e demandas expressas pelos atores sociais no presente, e interpreta o seu potencial para levar na direção de uma sociedade melhor e mais humana (Benhabib, 1986, p. 226, grifo meu) 
Muito embora Habermas tenha um papel fundamental na história que Benhabib (1986) reconstrói da teoria crítica, a avaliação que ela faz é a de que ele talvez não tenha deixado o espaço necessário para a perspectiva da "transformação radical” à qual ela se refere na passagem acima citada. De um lado, um dos seus grandes méritos foi ter "restaurado o momento de genuína colaboração entre as ciências sociais e a filosofia e ter desenvolvido uma teoria diagnóstico-explicativa empiricamente frutífera das sociedades de capitalismo tardio" (Benhabib, 1986, p. 227). Com isso Habermas supre um déficit dos autores da Escola de Frankfurt que, de acordo com Benhabib, não teriam dado conta da dimensão diagnóstico-explicativa da teoria crítica e, consequentemente, não teriam sido capazes de ancorar no presente a razão (meramente) utópica almejada por eles. Em síntese, a partir da Dialética do Esclarecimento a teoria crítica teria se reduzido à crítica utópica-antecipatória sem ser capaz de explorar as contradições do presente. Como para Benhabib a tarefa da teoria crítica é "mostrar o potencial para a racionalidade e a emancipação implícitos no presente" (Benhabib, 1986, p. 225), ela comemora o fato de Habermas ter restaurado a colaboração entre as ciências sociais e a filosofia de maneira mais produtiva e empiricamente embasada. Não apenas, Habermas também fez a crítica filosófica do paradigma da ação como obra e procurou mostrar que o modelo comunicativo จิ é mais frutífero do ponto de vista científico-soo cial. No entanto, mesmo tendo provocado uma . mudança importante de paradigma e procurado ฮิ suprir o déficit da geração anterior, Benhabib F entende que Habermas não foi capaz de romper $\dot{2}$ inteiramente com as amarras que aprisionavam ले os seus antecessores na camisa de força da filo-

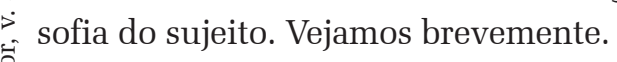

Para se contrapor ao projeto meramente utópico de Adorno e Horkheimer, Habermas retoma o legado da modernidade para defender que a emancipação não exige a rejeição desse legado cultural - e da racionalidade comunicativa -, mas sim a reversão da dinâmica destrutiva do capitalismo (Cf. Benhabib, 1986, p. 253-254). Não cabe nos limites estreitos deste texto uma análise acurada da avaliação que Benhabib faz em Critique, norm, and utopia das características centrais da modernidade cultural de acordo com Habermas. Basta lembrar que, para ela, neste momento, Habermas flerta com as especulações da filosofia da história, semelhantes às que ela havia, em sintonia com Arendt, detectado em Marx e em Hegel. O ponto é que Habermas exagera em tornar as características da modernidade cultural - descentramento, reflexividade e diferenciação das esferas de valor - critérios vinculantes da modernidade. É "excessivamente forte" a tese de que os constituintes da modernidade cultural são os critérios vinculantes da racionalidade. Ela pergunta: "Por que não vemos esse processo como um processo contingente, sem cairmos no páthos da história universal, ao fim da qual as estruturas conceituais de nosso mundo surgem como constituintes de uma racionalidade tout court?" (Benhabib, 1986, p. 255). Parafraseando Arendt - para quem Marx acaba colocando Hegel novamente de cabeça pra cima -, Benhabib estaria dizendo que Habermas coloca novamente a filosofia do sujeito de "cabeça pra cima".

É verdade que Seyla Behabib está alinhada com as intenções filosóficas de fundo da teoria do agir comunicativo, pois, é para se contrapor ao niilismo resultante de uma relação relutante com o legado da modernidade (de Nietzsche, Heidegger, Adorno e Horkheimer na Dialética do esclarecimento e Sartre, por exemplo) que Habermas contra-ataca afirmando que este legado é "vinculante para nós". Como ele, Benhabib se preocupa com o niilismo, entre outras coisas, porque bloqueia a percepção das contradições do presente: nisso estão alinhados. Mas a tentativa de escapar do niilismo teria levado Habermas a pecar, no extremo oposto, por excesso de racionalismo parecendo supor que nós estamos na marcha certa, no caminho correto, bastando apenas completarmos o percurso em andamento. O futuro (a emancipação) parece 
ser uma consequência necessária do presente. Benhabib enxerga o "pathos da história universal" entrando novamente em cena e, junto com ele, uma visão mais reformista do que propriamente transformadora e transfiguradora do presente. Este movimento distancia Habermas do niilismo, mas ao preço de talvez bloquear a tarefa do teórico crítico de pensar a emancipação à luz de um futuro melhor (o que ela vai procurar corrigir com a sua utopia "comunicativa”, fortemente inspirada em Arendt).

É importante notar que embora Benhabib tenha um posicionamento claro a respeito dos limites das abordagens neo-aristotélicas (de MacIntyre, por exemplo) e pós-modernas (Foucault e Lyotard) - limites resultantes de um questionamento sem nuances do legado da modernidade - nem por isso ela aceita a tese habermasiana do aumento crescente da racionalidade, concomitante com um processo cumulativo de aprendizado (Cf. Benhabib, 1986, p. 262). Se, para Habermas, a modernidade implica aumento de reflexividade e, para Foucault, aumento da dominação (Cf. Benhabib, 1986, p.254), ela, por sua vez, parece ficar filosoficamente mais confortável a uma distância segura dos dois extremos, pois ambos assumem, ao fim e ao cabo, ares de necessidade, sufocando o espaço da contingência (a "neo-aristótelica” Hannah Arendt parece abordar Benhabib também neste aspecto, de valorização da contingência e de recusa dos extremos teóricos viciosos). Se abandonamos a ideia do progresso automático, Habermas e Foucault estão até certo ponto corretos, pois, o avanço do aprendizado e da reflexividade pode implicar também em novas formas de repressão (Cf. Benhabib, 1986, p. 271). As duas coisas. Não uma ou outra. Não necessariamente uma mais do que outra. Aqui Benhabib parece ecoar a rejeição arendtiana dos arautos do progresso, bem como da ruína.

Desde pelo menos Origens do totalitarismo Arendt fazia questão de antagonizar com aqueles que ela denominava "ideólogos" do progresso ou da ruína: Progresso e ruína são "duas faces da mesma moeda", pois resultam de uma certa superstição que resiste a encarar a realidade sem preconceitos (Arendt, 2004. p. 12). ${ }^{13}$ Teóricos de um lado ou do outro costumam ajeitar o mundo conforme as suas próprias expectativas, conforme seu "otimismo" ou "desespero", e, assim, tendem a desmerecer as especificidades dos fenômenos e, claro, a apagar as contradições existentes no presente (por isso Arendt os chama "ideólogos", pois ideologias lidam mal com as experiências e pessoas reais, vivem de sínteses e não de contradições [Cf. Arendt, 2004, p. 522] ${ }^{14}$ ). Além de desconfiar profundamente dos extremos e considerá-los (aristotelicamente) igualmente “imprudentes”, Arendt não esconde que ambos sustentam atitudes teóricas semelhantes, pois, tanto os teóricos do progresso quanto os da ruína estão interessados naquelas forças que atuam por trás das nossas costas e por algum tipo de necessidade que nos escapa. Caso admitamos, "como ambos fazem, que existe algo de semelhante a um processo histórico com uma direção definível e um fim previsível, obviamente ele só poderá nos conduzir ao paraíso ou ao inferno" (Arendt, 1992, p. 138). No âmbito da filosofia, Hegel é o representante exemplar da linhagem do progresso, mas ele não está sozinho evidentemente. Quando a era moderna começa a reagir à suspeita e ao desespero inaugurados pela dúvida cartesiana, tende ao extremo oposto de um otimismo bastante exagerado com o progresso. A Revolução Francesa teria contribuído para inverter o humor instaurado por Descartes e sustentado pela "tribo de homens notoriamente melancólicos", os filósofos, que logo se tornaram "exultantes e otimistas", convertidos a uma fé no progresso não só do conhecimento, mas dos assuntos 13 "Este livro", diz Arendt no prefácio à primeira edição de Origens do totalitarismo, "foi escrito contra o pano de fundo tanto do otimismo imprudente quanto do desespero imprudente. Sustenta que Progresso e Ruina são dois lados da mesma moeda; que são ambos artigos de superstição não de fé" (Arendt, 2004, p. 12, tradução modificada).

${ }^{14}$ Em Entre o passado e o futuro, Arendt volta a criticar os arautos do progresso (os liberais) da ruina (conservadores) por serem igualmente precários na arte de fazer distinções (Arendt, 1992, pp. 132-5). 
humanos em geral, e da moral em particular (Arendt, 2002, p. 303). Para Arendt, este novo espírito está presente em Adam Smith, Kant, Hegel e Marx, para os quais "o progresso tornou-se o projeto da Humanidade, atuando por trás das costas dos homens reais - uma força personificada que iremos encontrar mais tarde na 'mão invisível' de Adam Smith, no 'ardil da natureza de Kant', na 'astúcia da razão' de Hegel, e no 'materialismo dialético' de Marx" (Arendt, 2002, p. 302). Se fosse Benhabib autora da frase (desconfio que poderia ser), talvez o "modelo evolucionário" de Habermas entrasse na lista (Cf. Benhabib, 1986, p. 274-278).

Voltando à Critique, norm, and utopia, Benhabib entende que Habermas flerta com o evolucionismo da ideia de progresso quando parece supor que "os processos de modernização cultural são em certo sentido irrevogáveis" (Benhabib, 1986, p.275). Ao afirmar que valores burgueses tais como o cientificismo e a moralidade universalista são " "desenvolvimentos irresistíveis, que seguiram uma lógica interna’ e que só podem ser revertidos ao custo de regressões", Habermas reproduz as mesmas conotações "especulativas da filosofia da história" (Benhabib, 1986, p. 276). Tal como Arendt havia notado a respeito das filosofias do progresso, para Benhabib as teorias evolucionárias achatam o horizonte do futuro "fazendo com que o futuro apareça como consequência necessária do presente" (Benhabib, 1986, p. 277). Resta จิ lugar para a ação? E para a transformação? Se i. O problema de Adorno e Horkheimer era que a \&े concepção utópica de razão não encontrava ancoramento algum no presente, o problema com †े Habermas é que a sua concepção de razão "pa$\therefore$ rece de tal modo um resultado natural do pre今 sente que é difícil ver o que poderia constituir

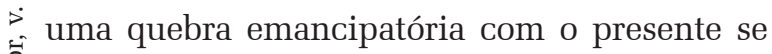
a racionalidade comunicativa fosse realizada" (Benhabib, 1986, p. 277). Em alguns aspectos - não periféricos - Habermas permanece enredado na filosofia do sujeito.

"Claramente Habermas rejeita de maneira categórica as duas primeiras premissas" da filosofia do sujeito, nota Benhabib, atribuindo a ele a "distinção crucial" entre trabalho [labor] e interação, e chamando atenção para a característica inegavelmente intersubjetiva da razão comunicativa (Benhabib, 1986, p. 330). No entanto,

Habermas reverte para o discurso da filosofia do sujeito naqueles pontos em sua teoria quando a reconstrução das competências da espécie de um sujeito anônimo - a humanidade como tal - não permanece meramente uma hipótese frutífera de pesquisa, mas assume o papel de uma narrativa filosófica da história formativa do sujeito da história (Benhabib, 1986, p. 330-331).

Tal como Hegel na Fenomenologia do Espírito, Habermas, em suas reconstruções, parece falar "em nome de um nós fictício" que (como havia notado Arendt a respeito de Hegel) é o ponto de vista a partir do qual a "história da história é contada" (Benhabib, 1986, p. 331). Ora, pergunta Benhabib, "quem é este "nós"” com o qual, no processo da evolução cultural, todos poderiam se identificar? Vale para homens, mulheres, judeus e gentios? Vale para todos, enfim? O problema, nada marginal, é a suspeita de que "essa evolução seja, na verdade, a lógica da história de apenas um grupo" (Benhabib, 1986, p. 330, nota 109). É a preocupação arendtiana com a dificuldade dos filósofos de lidarem com a pluralidade humana que retorna novamente em Critique, norm, and utopia, agora com relação a Habermas. Aquela "Humanidade" que Arendt identificou na filosofia da história como artificio filosófico para reduzir a pluralidade humana a um sujeito único (One Man), Benhabib desconfia retornar em Habermas: este "nós" é uma singularidade coletiva, a "humanidade enquanto tal". Corre-se o risco de esquecer, salienta Benhabib, que uma coletividade se forma não por artificio teórico, "mas a partir dos esforços morais e políticos dos atores em luta" (Benhabib, 1986, p. 331, grifo meu). Isso lembra as tantas vezes que Arendt ressaltou que os filósofos, desde o acorde fundamental soado por Platão (assim como os teóricos políticos de linhagem 
liberal ou marxista), estão sempre em busca de uma harmonia na sociedade que mascara o fato inelutável de que, onde há pluralidade, há instabilidade, e conflito, "vontades e intenções conflitantes" (Arendt, 2010, p.230); "luta” conforme Benhabib. Como Arendt, Benhabib resiste às tentativas reiteradas dos filósofos de instaurarem harmonia, linearidade, "predição científica" (Arendt, 2010, p. 53) e comportamento uniforme onde não há. $\mathrm{O}$ "discurso filosófico objetificante”, como Benhabib notou a respeito de Hegel, revela profunda rejeição à intersubjetividade (Benhabib, 1986, p. 87-88).

\section{CONCLUSÃO}

Neste artigo eu procurei mostrar que a tese de Seyla Benhabib segundo a qual a tradição da teoria crítica permanece vinculada à filosofia do sujeito espelha os aspectos mais relevantes da crítica arendtiana à filosofia política ocidental. Termino sublinhando que essa crítica de matriz arendtiana à tradição não significa, entretanto, que Benhabib deixe de atribuir à filosofia a tarefa fundamental de justificação normativa, tanto quanto a crítica aos exageros racionalistas de Habermas não a leva a abraçar o decisionismo (Cf. Benhabib, 1986, p. 327). Do mesmo modo, a crítica da filosofia do sujeito não implica aderir à filosofia sem sujeito do pós-estruturalismo (Cf. Benhabib, 1986, p. 55). A tarefa filosófica assumida a partir de Critique, norm, and utopia é delicada porque envolve rechaçar os excessos racionalistas da tradição na qual ela mesma quer se inserir sem municiar o ceticismo generalizado dos anos finais do século XX com relação aos ideais filosóficos modernos de "racionalidade", "autonomia" e "reflexão". Em outras palavras, a crítica (de inspiração arendtiana) que Benhabib faz da filosofia do sujeito - contra discursos filosóficos “objetificantes” que minam as condições para uma consideração filosófica da intersubjetividade e da pluralidade humana com as suas indeterminações - não quer contribuir para fomentar a desconfiança com relação a todo e qualquer "programa filosófico que ainda busca formular um critério mínimo de conhecimento e ação" (Benhabib, 1986, p. 14).

Benhabib tem uma disposição teórica inegável para colocar em diálogo tradições teóricas rivais, pois está ciente de que oposições teóricas agudas e simplórias não dão conta dos enormes desafios do nosso tempo (Cf. Benhabib, 1992, p. 2-3). Procurei sugerir neste texto que esta talvez seja outra característica herdada de Arendt, que sempre se manifestou criticamente contra os arautos da ruína e do progresso e rechaçou como igualmente problemáticas as expectativas liberais e marxistas de harmonia social (Cf. Benhabib, 1986, p.348). Aristotelicamente, ambas parecem dispostas a encontrar medianias teóricas entre extremos incapazes de enfrentar as vicissitudes e as contradições da ação. Não à toa, a combinação sui generis de elementos aristotélicos e kantianos contida na teoria arendtiana do juízo servirão de forte inspiração para Benhabib defender, nos textos reunidos em Situtaing the self, uma ética de princípios sensível ao contexto.

Por fim, cumpre destacar que a crítica do hipermodernismo reformista de Habermas leva Benhabib, ao final de Critique, norm, and utopia, a reivindicar o aspecto originário utópico da teoria crítica, que ele teria abandonado junto com a sua crença no progresso. Exagero ou não, com relação a Habermas, importa notar que a utopia de Benhabib é comunicativa e almeja que os interesses, os desejos, as necessidades, os pontos de vista das pessoas sejam passíveis de serem comunicados, discutidos publicamente, reformulados e transformados (Benhabib, 1986, p.352). Embora Hannah Arendt desconfiasse tremendamente de projetos utópicos (Cf. Arendt, 1992, p.41), Benhabib desenhará os contornos da sua utopia comunicativa em diálogo rente com a filosofia prática arendtiana. Mas este é assunto para outro texto. Recebido para publicação em 11 de fevereiro de 2020
Aceito em 23 de julho de 2020 


\section{REFERÊNCIAS}

ARENDT, H. "Philosophy and Politics: the problem of action and thought after the French Revolution" lecture, 1954 (3 of 4 folders). In: Hannah Arendt Papers, Manuscript Division, Library of Congress, Washington, D.C, 1954.

Entre o passado e o futuro. São Paulo: Editora Perspectiva, 1992.

"Só permanece a língua materna". In: $A$ dignidade da Política. Rio de Janeiro: Relume-Dumará, 1993, pp. 123-143.

A Vida do Espírito. Rio de Janeiro: RelumeDumará, 2002

Origens do totalitarismo. São Paulo: Companhia das Letras, 2004.

"De Hegel a Marx". In: A Promessa da Política. Rio de Janeiro: Difel, 2009, pp. 118-130.

A condição humana. São Paulo: Forense Universitária, 2010.

BENHABIB, S. Critique, norm, and utopia. A study of the foundations of Critical theory. New York: Columbia University Press, 1986.
Situating the self. Gender, community and postmodernism in contemporary ethics. New York: Routledge, 1992.

The Reluctant Modernism of Hannah Arendt. Oxford: Rowman \& Littlefield Publishers, 2000.

Concrete Universality and Crítical Social Theory: Dialogue with Alfredo Gomez-Muller and Gabriel Rockhill”. In: GOMEZ-MULLER, Alfredo; ROCKHILL, Gabriel (Orgs.). Politics of Culture and the Spirit of Critique: Dialogues. Nova York: Columbia University Press, 2012, p. 48-65.

DUARTE, A. O pensamento à sombra da ruptura: política e filosofia em Hannah Arendt. São Paulo: Paz e Terra, 2000.

FRATESCHI, Y. Universalismo interativo e mentalidade alargada em Seyla Benhabib: apropriação e crítica de Hannah Arendt.Ethic@, Florianópolis, Santa Catarina, v. 13, n.2, pp. 363-385, jul-dez, 2014

Juízo e Opinião em Hannah Arendt. Cadernos de Filosofia Alemã: Crítica e Modernidade, São Paulo, v. 24, n. 1, p. 35-65, 2019.

LOPES, A.C. Norma e utopia: A transformacão da ética do discurso na teoria crítica de SeylaBenhabib. Tese (Doutorado em Filosofia). Programa de Pós Graduação em Filosofia, Campinas: Unicamp - IFCH, 2019. 


\section{SEYLA BENHABIB WITH HANNAH ARENDT AGAINST THE PHILOSOPHY OF THE SUBJECT}

\author{
Yara Frateschi
}

From Situating the self: gender, community and postmodernism in contemporary ethics (1992), we know that SeylaBenhabib answers Habermas' excesses and the limits of the modern universalist tradition with a reinterpretation of the Arendtian conception of "enlarged thought". In this article, I propose to show that Arendt's presence in Benhabib's thought is even more radical than it seems at first, because the author of The human condition is at the root of Benhabib's theoretical project, guiding her in her philosophical confrontation with tradition at her first major work,Critique, norm, and utopia: a study of the foundations of Crítical theory(1986). My interpretive hypothesis is that the central thesis of this book, according to which Crítical theory is haunted by the philosophy of the subject, bears the marks of Arendt's criticism to Western political philosophy.

KEYwORDS: Hannah Arendt. Seyla Benhabib. Philosophy of the Subject. Political Philosophy. Plurality.

\section{SEYLA BENHABIB AVEC ARENDT CONTRE LA PHILOSOPHIE DU SUJET}

\author{
Yara Frateschi
}

A partir des textes rassemblés dans le livre Situating the self: gender, community and postmodernism in contemporary ethics (1992), on sait que Seyla Benhabib répond aux excès rationalistes d'Habermas et aux limites de la tradition universaliste moderne par une réinterprétation de la conception arendtienne du «mentalité élargie». Dans cet article, je propose de montrer que la présence d'Arendt dans la pensée de Benhabib est encore plus radicale qu'il n'y paraît au premier abord, car Arendt est à l'origine de son projet théorique guidant la confrontation philosophique que Benhabib fait avec tradition, dans son premier grand ouvrage, Critique, norm, and utopia: a study of the foundations of crítical theory (1986). Mon hypothèse interprétative est que la thèse centrale de ce livre, selon laquelle la théorie critique est hantée par la philosophie du sujet, porte les marques de la critique arendtienne de la philosophie politique occidentale.

Mots-CLés:Hannah Arendt. SeylaBenhabib.Philosophie du sujet. Philosophie politique. Pluralité.

Yara Frateschi - Doutora em Filosofia pela Universidade de São Paulo. Professora Livre Docente do Departamento de Filosofia da Universidade Estadual de Campinas. Bolsista de Produtividade em Pesquisa do CNPq. Desenvolve pesquisas na área de ética, filosofia política e teoria crítica. Publicou, entre outros, o livro A física da política: Hobbes contra Aristóteles pela Editora da Unicamp (2008) e é autora de Liberdade, cidadania e ethos democráticos (Editora Alameda, no prelo). 
